\title{
The influence of a diffusive boundary layer on early organic matter and calcium carbonate diagenesis
}

\author{
OLIVIER SULPIS ${ }^{1}$, MONICA MARTINEZ WILHELMUS ${ }^{2}$, \\ MATTHEW P HUMPHREYS ${ }^{3}$, DUSTIN CARROLL ${ }^{4}$, WILL \\ BERELSON $^{5}$, DIMITRIS MENEMENLIS ${ }^{6}$, JACK \\ MIDDELBURG $^{7}$ AND JESS ADKINS $^{8}$ \\ ${ }^{1}$ Department of Earth Sciences \\ ${ }^{2}$ University of California Riverside \\ ${ }^{3} \mathrm{NIOZ}$ Royal Netherlands Institute for Sea Research \\ ${ }^{4}$ Moss Landing Marine Laboratories, San José State University \\ ${ }^{5}$ University of Southern California \\ ${ }^{6}$ Jet Propulsion Laboratory \\ ${ }^{7}$ Utrecht University \\ ${ }^{8}$ California Institute of Technology \\ Presenting Author: o.j.t.sulpis@uu.nl
}

The diffusive boundary layer (DBL) is a thin fluid layer that extends a few hundred microns to millimeters above the sediment-water interface. In the DBL, molecular diffusion is the dominant mode of solute transport and laboratory experiments of sediment calcium carbonate $\left(\mathrm{CaCO}_{3}\right)$ dissolution in seawater suggest that diffusion through the DBL is the rate-limiting step for $\mathrm{CaCO}_{3}$ dissolution at the seafloor. Nevertheless, earlier assessments of in situ $\mathrm{CaCO}_{3}$ dissolution at the sediment-water interface in the central equatorial Pacific indicated that DBL thickness does not impact overall dissolution rates (Berelson et al., 1994). Here, using a diagenetic model that incorporates the latest $\mathrm{CaCO}_{3}$ dissolution kinetics, organic-matter degradation, and a DBL above the sediment-water interface, we examine reasons for this apparent inconsistency.

We show that DBL control of benthic $\mathrm{CaCO}_{3}$ dissolution is a function of both organic matter flux to the seafloor and bottomwater saturation state with respect to $\mathrm{CaCO}_{3}$. In shallower, supersaturated waters, thicker DBLs trap organic-matter degradation by-products in sediment porewaters and in most cases favor $\mathrm{CaCO}_{3}$ dissolution. In deeper, undersaturated waters, thicker DBLs maintain sediment porewater near equilibrium with respect to $\mathrm{CaCO}_{3}$ and thus facilitate $\mathrm{CaCO}_{3}$ preservation. Regardless of the bottom-water saturation state with respect to $\mathrm{CaCO}_{3}, \mathrm{DBL}$ thickness strongly affects the depth distribution of porewater solutes and should be taken into account when interpreting measured or reconstructed sedimentary $\mathrm{pH}$ profiles. More broadly, our modeling results stress that the DBL is a diffusion barrier that acts in both directions. In sediments subject to a strong organic matter delivery, thicker DBLs can inhibit oxygen penetration and promote porewater anoxia, thus affecting both sediment chemistry and biology.

\section{Reference:}

Berelson, W.M., Hammond, D.E., McManus, J. and Kilgore, T.E. (1994) Dissolution kinetics of calcium carbonate in equatorial Pacific sediments. Global Biogeochemical Cycles 8, 219-235. 